\title{
A TUTORIA ACADÊMICA DO PROGRAMA DE MESTRADO PROFISSIONAL EM EDUCAÇÃO: FORMAÇÃO DE FORMADORES, DA PUC-SP: um espaço de aprendizagem colaborativa e crítica \\ THE ACADEMIC TUTORING OFICIAL THE EDUCATIVE PROFESSIONAL MASTER'S PROGRAM: PUC- SP, DEVELOPMENT OFICIAL TRAINERS: a space for collaborative and reflective learning
}

\section{Luciana Andréa Afonso Sigalla', Maria Emiliana Lima Penteado², Rodnei Pereira ${ }^{3}$}

\author{
${ }^{1}$ Doutora e mestra em Educação: Psicologia da Educação, PUC-SP. Integrante do grupo de pesquisa Contexto \\ Escolar, Processos Identitários da Formação de Professores e Alunos da Educação Básica (CEPId)/CNPq, da PUC- \\ SP. - luciana.sigalla@gmail.com \\ ${ }^{2}$ Doutora e mestra em Educação: Psicologia da Educação, PUC-SP. Integrante do grupo de pesquisa GADS/CNPq, \\ da PUC-SP. Professora nas Faculdades Integradas Campos Salles e coordenadora pedagógica na Prefeitura Munic- \\ ipal de São Paulo. \\ ${ }^{3}$ Doutor e mestre em Educação: Psicologia da Educação, pela PUC-SP. Professor e pesquisador na Universidade \\ Paulista. Bolsista da Fundação Carlos Chagas
}

Recebido em 14 de Agosto de 2018; Aceito em 16 de Outubro de 2018.

\begin{abstract}
Resumo
Este trabalho propõe-se a analisar as contribuições de uma prática de tutoria acadêmica - desenvolvida em um programa de mestrado profissional em educação da cidade de São Paulo - para tutores e alunos tutorados que participaram dessa atividade no período de 2013 a 2016. Focaliza as interações entre os envolvidos e seus efeitos nos processos de aprendizagem que ocorrem na pós-graduação stricto sensu, especialmente para os alunos do referido programa. Os dados foram produzidos a partir de pesquisa bibliográfica e do uso de questionário, contendo questões abertas, a tutores e a alunos tutorados. O referencial teórico adotado fundamentou-se na perspectiva sócio-crítica da formação de professores e na psicologia sócio-histórica. Os resultados indicaram que a tutoria acadêmica se constituiu como um espaço de aprendizagem colaborativa e crítica para todos os participantes da pesquisa e que o mestrado profissional em educação, por sua natureza, tem contribuído positivamente não apenas para os tutorados, alunos do programa, mas também para os tutores, em sua maioria doutorandos de outros programas de pós-graduação em educação, da mesma instituição.
\end{abstract}

Palavras-chave: Tutoria acadêmica. Mestrado profissional em educação. Aprendizagem colaborativa e crítica.

\begin{abstract}
This article intends to analyze the contributions of an academic tutoring oficial practice - developed in a educational professional master's program in São Paulo - to tutors and students who participated in this activity between 2013 to 2016. Focalizes the interactions between those involved and their effects on the learning worked methods in the postgraduate, especially for the students of the mentioned program. The information collected were produced from bibliographical research and the use of a questionnaire, containing open questions, to tutors and to students. The theoretical framework adopted was based on the socio-critical perspective of teacher training and socio-historical psychology. The results indicated that academic tutoring was a collaborative and reflective learning space for all the research participants and that the professional master's degree in education, by its characteristics, has contributed positively not only to the students, but also for tutors, mostly doctoral students of other postgraduate programs in education, from the same institution.
\end{abstract}

Keywords: Academic tutoring. Educative Master's degree. Collaborative and reflective learning. 


\section{INTRODUÇÃO}

O presente artigo toma como objeto de reflexão as interações entre tutores e tutorados do Programa de Mestrado Profissional em Educação: Formação de Formadores (Formep), da Pontifícia Universidade Católica de São Paulo (PUC-SP), problematizando como tais interações colaboraram para que a tutoria acadêmica, atividade desenvolvida no referido programa, vem permitindo a construção de um espaço de aprendizagem colaborativa e crítica, tanto para tutores quanto para tutorados.

Para tanto, apresentamos, primeiramente, um breve histórico do surgimento dos cursos de Mestrado Profissional em Educação no Brasil e da criação do Formep, na PUC-SP. Na sequência, abordamos a prática de tutoria acadêmica realizada no referido programa de pós-graduação.

Em seguida, apresentamos a fundamentação teórica do estudo, pautada na perspectiva sócio-crítica da formação de professores e na psicologia sócio-histórica, evidenciando o conceito vigotskiano de Zona de Desenvolvimento Iminente (ZDI).

Dando prosseguimento, explicitamos o percurso metodológico da pesquisa e problematizamos as contribuições da tutoria acadêmica para os envolvidos. Finalizamos apresentando as conclusões, com a proposição de aprofundamento de estudos.

Do surgimento dos cursos de Mestrado Profissional em Educação no Brasil à criação do Mestrado Profissional em Educação: Formação de Formadores (Formep), da PUC-SP

Embora a Lei no 4.024/1961ํำ (BRASIL, 1961) seja o primeiro documento a fazer referência a cursos de pós-graduação no Brasil, foi a publicação do Parecer CFE no 977/1965 (BRASIL, 1965) que marcou a institucionalização desse nível de ensino no país. Segundo Cury (2005, p. 14), o parecer seria a "referência constante das outras normatizações que se lhe seguiram e para a solução de questões suscitadas na implantação dos programas e dos cursos".

A ideia do Mestrado Profissional (MP) já estava, de certa forma, expressa no referido documento, conforme evidenciam os fragmentos a seguir (BRASIL, 1965, s.p. - Grifos nossos):

De qualquer modo, o desenvolvimento do saber e das técnicas aconselha introduzir na universidade uma espécie de diversificação vertical com o escalonamento de níveis de estudo que vão desde o ciclo básico, a graduação até a pós-graduação. Haveria desta forma uma infra-estrutura correspondente ao plano do ensino [referindo-se à graduação], cujo objetivo seria, de um lado a instrução científica e humanista para servir de base a qualquer ramo, e doutra parte teria por fim a formação profissional; e uma superestrutura destinada à pesquisa [referindo-se à pós-graduação], cuja meta seria o desenvolvimento da ciência e da cultura em geral, o treinamento de pesquisadores, tecnólogos e profissionais de alto nível.

A pós-graduação torna-se, assim, na universidade moderna, cúpula dos estudos, sistema especial de cursos exigido pelas condições da pesquisa científica e pelas necessidades do treinamento avançado. $O$ seu objetivo imediato é, sem dúvida, proporcionar ao estudante aprofundamento do saber que lhe permita alcançar elevado padrão de competência científica ou técnico-profissional, impossível de adquirir no âmbito da graduação.

A Lei no 4.024/1961 é a primeira Lei de Diretrizes e Bases da Educação Nacional (LDBEN) promulgada no país. 
Apesar de o parecer já expressar nitidamente a ideia de MP, foi apenas em 1998, mais de trinta anos após sua aprovação e homologação, que a modalidade foi criada no Brasil, com a publicação da Portaria no 80/1998 (BRASIL, 1998), que dispõe sobre o reconhecimento dos mestrados profissionais.

Nesse processo de consolidação e ampliação dos cursos de MP no país, uma década depois, foi publicada a Portaria Normativa no 7/2009 (BRASIL, 2009a), que dispõe sobre o Mestrado Profissional no âmbito da Capes, a qual foi revogada, logo em seguida, pela Portaria Normativa no 17/2009 (BRASIL, 2009b), devido a algumas alterações em seu texto.

Oito anos após a homologação desta última, que regulamentava até então o MP, surgiu a Portaria no 389/2017 (BRASIL, 2017), que dispõe sobre o Mestrado e o Doutorado Profissional, no âmbito da pós-graduação stricto sensu.

É importante destacar que o ano de 2009 seria marcado não apenas pela publicação da Portaria Normativa no 7/2009 (BRASIL, 2009a), mas também pela criação do primeiro curso de Mestrado Profissional em Educação (MPE) no Brasil: o Mestrado Profissional em Gestão e Avaliação da Educação Pública, da Universidade Federal de Juiz de Fora (UFJF), segundo o Documento do Forpred (2013).

Após quase uma década da criação do primeiro curso no país, há, atualmente, 46 cursos $^{2}$ de MPE em funcionamento, avaliados e aprovados pela Capes, oferecidos nas cinco regiões brasileiras, o que evidencia sua franca expansão no Brasil.

Nesse contexto, em 2012, um grupo de professoras do Programa de Estudos Pós-Graduados em Educação: Psicologia da Educação (PED), da Pontifícia Universidade Católica de São Paulo (PUC-SP), decidiu elaborar uma proposta de pós-graduação stricto sensu "que atendesse a uma necessidade das redes de ensino e de outros espaços educativos, qual seja, a formação de profissionais que atuam na gestão pedagógica" (ANDRÉ, 2012, p. 215), dando origem ao Programa de Estudos Pós-Graduados em Educação: Formação de Formadores (Formep), nível Mestrado Profissional.

Aprovado pela Capes em dezembro de 2012, o Formep, destinado a coordenadores pedagógicos, diretores, supervisores e professores das redes pública e privada de ensino, deu início às suas atividades na PUC-SP em agosto de 2013, caracterizando-se:

[...] por promover a articulação entre pesquisa e prática pedagógica na formação do formador [...] entendido como o profissional que faz a mediação entre os profissionais da educação, os alunos e os conhecimentos, visando a qualificação da ação educativa e suas implicações no planejamento, na ação pedagógica e na avaliação (PUC-SP, 2015, p. 6, art. 18 - Grifo nosso).

De acordo com André e Príncepe (2017, p. 106), o foco do Programa "na formação do formador de professores da educação básica decorre do papel fundamental que esse profissional ocupa na efetivação do trabalho pedagógico nas escolas ou em outras instituições educativas".

Embora o formador de professores em contexto de trabalho - na maioria das vezes, papel desempenhado pelo coordenador pedagógico - seja peça-chave nas escolas de Educação Básica, o Formep é o único curso de MPE destinado a esse público, o que o torna pioneiro no Brasil³ (ANDRÉ; PRíNCEPE, 2017).

2

O dado refere-se apenas aos cursos de Mestrado Profissional em Educação avaliados e reconhecidos pelas Capes. Disponível em: https:// sucupira.capes.gov.br/sucupira/public/consultas/coleta/programa/quantitativos/quantitativoAreaConhecimento.jsf?areaAvaliacao $=38$. Acesso em: 09 jul. 2018. 
Em estudo realizado por Reis, Sigalla e Penteado (2015) acerca das origens do Formep, as autoras entrevistaram seis professoras que participaram do processo de implantação do Programa, desde sua idealização.

Com os dados produzidos nas entrevistas, as autoras concluíram que o Formep teve origem:

[...] a partir dos incômodos das professoras entrevistadas com questões relacionadas a atender às necessidades formativas dos alunos que já atuavam na educação, respondendo a uma demanda de profissionais que almejavam aperfeiçoar sua prática profissional de maneira mais específica (REIS; SIGALLA; PENTEADO, 2015, p. 7064).

Segundo as autoras, a pesquisa revelou que as percepções das professoras entrevistadas sobre a gênese do Programa revelaram aspectos pessoais seus e de seus projetos de vida, pois elas:

[...] ao falarem das origens do Programa, também falaram de suas concepções de educação, de ser humano e de mundo, evidenciando que não é qualquer profissional que se envolve em causas concretas para oferecer melhor qualidade à educação brasileira. Para isso, é preciso ser, antes de tudo, um ser humano consciente de sua atuação política e social no mundo (REIS; SIGALLA; PENTEADO, 2015, p. 7065).

As autoras concluíram, ainda, que as professoras tinham objetivos em comum, dentre os quais melhorar a Educação Básica e colocar à disposição seus conhecimentos, acumulados por anos de experiência na área da Educação. Dessa forma, elas trabalharam juntas para concretizar, coletiva e colaborativamente, algo que era importante em suas vidas: constituir o Formep.

Estruturado por uma área de concentração denominada Formação de Formadores: Ação Pedagógica e Avaliação, o Programa está organizado em torno de duas linhas de pesquisa: (1) Desenvolvimento profissional do formador e práticas educativas e (2) Intervenções avaliativas em espaços educativos (PUC-SP, 2015).

De acordo com André e Príncepe (2017), a estrutura curricular do Formep é composta: por um conjunto articulado de disciplinas obrigatórias e eletivas; pelo trabalho final e por duas atividades complementares, quais sejam, a tutoria acadêmica e o seminário de práticas.

Com relação à tutoria acadêmica, foco do trabalho ora apresentado, trata-se de uma atividade realizada voluntariamente por doutorandos - e, em alguns casos, mestrandos e pós-doutorandos - de diferentes Programas de Pós-Graduação em Educação da PUC-SP, que são convidados por seus professores e/ou orientadores para atuarem como tutores junto aos mestrandos ingressantes no Formep.

Logo no início do curso, esses alunos (tutorandos) são informados da tutoria acadêmica pela coordenação do Programa e orientados a inscrever-se em um dos grupos de tutoria, dos quais participarão quinzenalmente, durante os dois primeiros semestres do curso, em encontros realizados nas dependências da PUC-SP, com duração de uma hora cada.

Além dos encontros presenciais, sempre que necessário, tutores e tutorandos comunicam-se a distância, por meio de aplicativos, como WhatsApp e Skype, e e-mails, para suprir eventuais necessidades que surjam no intervalo entre os encontros quinzenais.

do o único MPE destinado à formação do formador de professores (em contexto de trabalho, ou seja, na formação continuada). Disponível em: http:// capes.gov.br/images/documentos/Relatorios_quadrienal_2017/20122017-Educacao_relatorio-de-avaliacao-quadrienal-2017_final.pdf. Acesso em: 09 
O foco de trabalho, na tutoria, é diferente em cada semestre. Sigalla (2018) explica que, no primeiro semestre, o foco é a escrita de um texto intitulado "Meu tema e eu", no qual os tutorandos definem seu tema de pesquisa no MP.

À medida que os encontros vão acontecendo e o trabalho vai sendo realizado, o texto de cada mestrando ganha diferentes versões, pois passa por um constante processo de aprimoramento, que se dá não apenas pelas trocas com os tutores - que intervêm no texto, de maneira dialógica - mas também com os próprios mestrandos, em momentos de socialização dos textos nos encontros (SIGALLA, 2018, p. 63).

Segundo a autora, a escrita do referido texto implica ao tutorando um exercício de narrar sua trajetória acadêmica e profissional, até seu ingresso no Formep. Nesse processo, em algum momento da escrita do "Meu tema e eu", "ele se depara com situações que o incomodam no ambiente de trabalho (a escola), que podem estar relacionadas à aprendizagem dos alunos, ao currículo, à avaliação ou às relações interpessoais, dentre tantas outras" (SIGALLA, 2018, p. 63).

Sigalla (2018, p. 63) aponta que:

Será nesse "confronto", e com a posterior reflexão sobre aquilo que o incomoda, que o mestrando identificará o que necessita responder ou compreender para transformar a realidade do local em que trabalha. Sua história, portanto, definirá a escolha de seu tema.

Já no segundo semestre do curso, o foco da tutoria é a escrita do texto "Meu tema e os outros", que tem como ponto de partida o texto produzido no primeiro semestre. Nesse momento, os tutorandos realizam uma revisão bibliográfica sobre o tema de pesquisa, por meio de oficinas realizadas nos encontros de tutoria, nas quais os mestrandos aprendem a localizar trabalhos científicos (teses e dissertações) em diferentes meios digitais (Banco de Teses da Capes, Biblioteca Digital Brasileira de Teses e Dissertações, Google Acadêmico, dentre outros) e a sistematizar as informações obtidas em planilhas, para posterior elaboração do texto que sintetiza seus achados (SIGALLA, 2018).

É importante ressaltar que a produção de ambos os textos, em especial a do "Meu tema e os outros", é acompanhada pela professora da disciplina Pesquisa e Prática Reflexiva (ANDRÉ, 2016; ANDRÉ et al., 2016), e o propósito é que ambos se tornem um único texto introdutório do projeto de pesquisa, a ser agregado, posteriormente, ao trabalho final de conclusão de curso.

O auxílio acadêmico oferecido pelos tutores é tido como algo fundamental aos mestrandos do Programa, conforme apontam André et al. (2016, p. 39):

Ao ingressar na pós-graduação, os estudantes enfrentam muitos desafios, sobretudo se pensarmos nos currículos, nos sistemas de cumprimento de créditos, na demonstração de proficiência em língua estrangeira, nas práticas de leitura e produção de textos acadêmicos e na relação com os orientadores. [...] Por isso, faz-se necessário encontrar estratégias que permitam contemplar as diferenças de repertório intelectual, linguístico, cultural com que os estudantes ingressam na pós-graduação, para que elas não sejam reforçadas, mas consideradas, de modo a possibilitar a todos os estudantes as ferramentas para o seu sucesso acadêmico.

Quanto ao seminário de práticas, trata-se de uma atividade que tem como objetivo possibilitar a sistematização e a socialização dos trabalhos científicos (comunicações orais e pôsteres) elaborados pelos mes- 
trandos do Formep. A organização e a realização do seminário contam com o coletivo do Programa, na figura de seus alunos, professores, tutores, coordenação e assistente de coordenação. As apresentações dos trabaIhos são mediadas por professores do Programa e acompanhadas pelos tutores (ANDRÉ; PRÍNCEPE, 2017).

Em 2017, ocorreu a terceira edição do seminário de práticas, que teve como temática "O diálogo entre universidade e escola na formação de formadores: possibilidades e mudanças" e contou com a apresentação de 65 trabalhos (comunicações orais e pôsteres).

Segundo Sigalla (2018, p. 55), da primeira para a terceira edição do seminário:

[...] houve um aumento significativo no número de trabalhos apresentados [...] o que evidencia um maior envolvimento dos alunos na atividade, que, vale mencionar, também conta com a participação de egressos do Programa, nas apresentações de trabalhos.

Observa-se, com base nas informações apresentadas, que prática de tutoria acadêmica descrita neste estudo é composta de diversas atividades e que faz parte do desenvolvimento do próprio Programa, configurando-se como uma atividade curricular que não deve ser reduzida a uma ação de prevenção e de combate às dificuldades no processo formativo dos pós-graduandos, como se observará a seguir.

\section{O Formep como espaço formativo de participação colaborativa e crítica: uma discussão a partir do conceito vigotskiano de Zona de Desenvolvimento Iminente (ZDI)}

Na teoria de Vigotski (1995, 2000, 2004, 2006, 2007, 2009, 2010), as condições sociais em que o indivíduo está inserido devem ser consideradas essenciais ao seu desenvolvimento, pois a relação estabelecida entre o ser humano e seu entorno é determinante para sua constituição como ser único, particular e social ao mesmo tempo, sendo a realidade social fonte do desenvolvimento humano. Assim, ao estudarmos o processo de desenvolvimento, em qualquer idade, devemos ter em mente as implicações da situação social na constituição do sujeito e como surgem e se desenvolvem, nessa mesma situação social, as novas configurações que impulsionam e qualificam o desenvolvimento dos indivíduos.

Em seus escritos, Vigotski postulava que os estudiosos, até os mais perspicazes, debruçavam-se sobre aquilo que se pode realizar sozinho (visão retrospectiva de desenvolvimento), deixando de considerar uma "zona" de aprendizagem em processo de "maturação", ou seja, na iminência de saltar, qualitativamente, no processo de compreensão e de objetivação de conceitos, havendo, para tanto, a colaboração de um par mais experiente na relação. Nesse ponto, desenvolve-se a Zona de Desenvolvimento Imininente (ZDI) ${ }^{4}$.

É importante considerar que a obra de Vigotski foi ampliada na contemporaneidade e que, desse modo, conceitos como "maturação" e "desenvolvimento próximo" foram colocados em discussão por conta de erros de tradução e/ou por limitação do autor à época de sua pesquisa, como revelam os estudos de Prestes (2010).

É nesse ponto que se encontra uma importante contribuição de Vigotski para a Educação, em especial, para o processo de ensino e aprendizagem que ocorre na escola, pois, quando se investiga o que a criança pode fazer em colaboração, determina-se o desenvolvimento de amanhã (próximo). Desse modo, o professor não ensinará à criança aquilo que ela sabe fazer por si só, mas o que não sabe e pode fazer, se for ensinada e direcionada.

Podemos dizer que a proposição da ZDI marca uma concepção de desenvolvimento humano prospectivo e com a participação de um par mais experiente na relação estabelecida em uma determinada situação 
social. Isso significa considerar as possibilidades de aprendizagem de cada pessoa e/ou de cada grupo. No caso específico das formações de professores que visem ao desenvolvimento profissional docente, considerar como premissa as possibilidades de aprendizagem oferecidas pela ZDI é fator determinante para melhorar a qualidade das formações. Contudo, vale ressaltar que a colaboração requer a participação dos envolvidos e que esta deve ser investigada, considerando seu nível e sua qualidade.

Não podemos ser ingênuos em pensar que a participação em situação de duplas ou em grupos, com pares mais experientes, já garante, por si só, a aprendizagem e o desenvolvimento dos "menos experientes". Nos estudos de Chaiklin (2011), encontramos críticas sobre o uso comum do conceito vigotskiano de ZDI, que, segundo o autor, vem sendo amplamente divulgado nas pesquisas educacionais, levando a interpretações equivocadas da obra de Vigotski. Nas palavras de Chaiklin (2011, p. 661-662):

A concepção comum de zona de desenvolvimento próximo sustenta ou inspira uma visão de perfeição educacional segundo a qual o professor perspicaz (ou "sortudo") é capaz de ajudar uma criança a dominar, sem esforço e de forma prazerosa, qualquer conteúdo que esteja na programação do dia.

O autor chama a atenção para alguns problemas decorrentes dessa "visão perfeita", centrada no "pressuposto da assistência". Segundo Chaiklin (2011, p. 662), "não é a competência em si da pessoa mais conhecedora que se mostra importante; o importante é compreender o significado da assistência em relação à aprendizagem e desenvolvimento da criança". Em outras palavras, devemos estar atentos à qualidade da relação estabelecida entre os envolvidos em uma determinada situação educativa, pois, a nosso ver, é dela (da qualidade da relação) que depende e decorre ou não, em primeira instância, o processo de aprendizagem e de desenvolvimento dos participantes.

De acordo com os estudos de Sigalla (2018) sobre a tutoria acadêmica entre pares, um aspecto a ser considerado na relação estabelecida entre tutor e tutorado é a colaboração. A colaboração parece ser a grande responsável para qualificar o trabalho de tutoria. Em consonância com os estudos da autora, que também estão ancorados no conceito vigotskiano de ZDI, a aprendizagem entre pares está presente na situação colaborativa e impulsiona o desenvolvimento daqueles que assumem o compromisso com a tutoria. Embora a autora não se aprofunde na discussão, ela traz à tona o conceito de colaboração crítica discutido por Magalhães (2009), para evidenciar que não é qualquer colaboração que promove a aprendizagem e o desenvolvimento dos envolvidos em uma situação educativa, mas sim aquela que prima pela participação crítica e gera nos participantes a transformação necessária para a ampliação e o avanço de conhecimento.

Penteado (2017), em seus estudos sobre a dimensão subjetiva da docência, coloca em discussão a qualidade da participação dos professores em processos formativos e tece considerações críticas acerca das garantias legais e das reais possibilidades de esses profissionais terem garantidos os espaços de participação ativa, na escola ou em outras instâncias educacionais. A autora defende a importância da participação como geradora de desenvolvimento profissional e transformação social, especificamente nas políticas educacionais. Essa discussão corrobora com nosso entendimento acerca de como o Formep vem constituindo-se um espaço formativo que contempla a participação colaborativa e crítica dos educadores - tutores e tutorados do Programa -, pois oferece a eles, por meio de diferentes mediações, as condições necessárias para desenvolverem-se profissionalmente, ao mesmo tempo que atuam em suas realidades, a fim de provocar melhorias e transformá-las significativamente. 


\section{PERCURSO METODOLÓGICO}

Ao nos debruçarmos sobre o tema "tutoria", iniciamos um processo de revisão de literatura sobre o assunto, utilizando os descritores "tutoria", "tutoria pedagógica" e "mentoria" em quatro idiomas (português, inglês, francês e espanhol), em buscadores nacionais e internacionais, tais como: Scielo, Bireme, Lilacs, Banco de Teses da CAPES, Portal de Periódicos da CAPES/MEC e Google Acadêmico.

Nesse primeiro movimento, encontramos trabalhos que empregam aos descritores mencionados múltiplos significados e que se referem a diferentes experiências. Por isso, nosso primeiro movimento foi excluir os trabalhos que abordavam a tutoria em cursos de Educação a Distância (EaD).

Outro conjunto de trabalhos, sobretudo aqueles em língua inglesa, no campo da Educação, referem-se a programas de formação continuada de gestores escolares e professores, com base em modelos gerenciais e referenciais teóricos do campo da Administração.

Em língua francesa, a maioria dos trabalhos encontrados também se refere a processos de formação continuada de gestores e professores, ou ainda, de estudantes de licenciaturas. Em virtude disso, elegeu-se como descritor principal o termo "tutoria acadêmica", que ofereceu um considerável retorno de estudos em língua portuguesa e em língua espanhola, que tratam da tutoria no contexto acadêmico.

Priorizamos, então, os estudos que abordam o assunto no campo do Ensino Superior. No Brasil, localizou-se um conjunto de programas de tutoria acadêmica, sobretudo em universidades federais, de várias regiões do país.

Em função do tempo, dos recursos e das condições para a realização do presente estudo, limitamo-nos aos periódicos científicos. Foram analisados os resumos de 209 artigos encontrados. Destes, foram selecionados os que abordavam especificamente a tutoria acadêmica na pós-graduação, que totalizam seis trabaIhos, todos publicados, vale mencionar, há menos de 12 anos, o que pode sugerir a emergência do tema e sua relevância.

Em um trabalho que se propôs a problematizar em que medida a pós-graduação, no Brasil, compromete-se com a formação de docentes para o Ensino Superior, Bastos et al. (2011) anunciam a escassez de programas de formação docente nos programas de pós-graduação, bem como defendem que este deveria ser um espaço de desenvolvimento e de aprimoramento de competências docentes.

Para os autores, a docência no Ensino Superior é muito mais complexa do que a atividade de ministrar aulas. Eles apontam também que, em função dos modelos pedagógicos tradicionalmente empregados pelas instituições de Ensino Superior, seja na graduação ou na pós-graduação, os professores dificultam que os estudantes tenham atendimentos mais individualizados e sintonizados com suas necessidades de aprendizagem específicas.

Diante disso, apresentam a tutoria - definida por eles como o conjunto de atividades de orientação e de acolhimento personalizado de alunos novos no ambiente universitário - como uma função do professor que atua no Ensino Superior.

Torres e Sanchez (2008), ao se debruçarem sobre os processos de ensino e aprendizagem de adultos da pós-graduação, afirmam que a tutoria, também entendida por eles como uma atividade de atendimento individualizada a novos alunos, pode contribuir com estudantes cuja formação inicial é deficitária.

Em um trabalho que analisou as metodologias e os resultados de um programa de autoavaliação de alunos de um programa de pós-graduação em Sistemas de Informação, na Colômbia, Rendón Giraldo (2008) 
demonstrou que a atividade de tutoria acadêmica (nesse caso, realizada por professores como uma atividade de apoio a estudantes ingressantes no referido programa) foi apontada pelos alunos como uma das metodologias que trouxe mais qualidade à sua formação.

Já o estudo de Frías (2012), sobre a relação entre a tutoria acadêmica e o desenvolvimento de um habitus científico em um grupo de estudantes de pós-graduação mexicano, demonstrou que tal atividade contribuiu para que os estudantes desenvolvessem um conjunto de disposições acadêmicas que lhes permitiram exercer com mais rigor sua atividade de investigadores educativos. Segundo o pesquisador, as disposições de ordem epistemológica ocuparam um lugar central, levando os estudantes a produzir pesquisas melhores, em comparação com as produções científicas de alunos de turmas anteriores, que não tiveram contato com a tutoria.

Jimenez-Vásquez (2014) afirma que a tutoria (que compõe uma política de formação da Universidad Autónoma de Tlaxcala, México) é uma das ações que ocupam papel central na formação de estudantes de doutorado, durante o processo de planejamento e desenvolvimento de suas teses, por um "tutor interno" e, após a defesa, por um "cotutor externo", responsável pelo desenvolvimento profissional dos egressos.

Para a pesquisadora, essa tem sido uma das ações que intenta formar melhores professores e pesquisadores, articulando o sucesso de projetos pessoais e suas articulações com a melhoria dos contextos sociais nos quais atuam.

Valdés-Cuerbo et al. (2013), em uma investigação acerca do perfil de estudantes de um programa de pós-graduação de uma universidade mexicana, demonstraram que um grupo de alunos que participou de um programa de tutoria acadêmica declarou-se mais satisfeito que outro grupo que não participou do programa, em relação ao desenvolvimento de competências de investigação científica. Para os autores, o grupo que participou da tutoria apresentou, ainda, melhor desempenho e produtividade acadêmica.

Observou-se, nos trabalhos mencionados, ao menos dois consensos. O primeiro, refere-se a uma compreensão da tutoria como uma atividade de atendimento individualizado, ou realizada em pequenos grupos, desenvolvida por professores ou alunos veteranos, em programas de pós-graduação, cuja intenção é favorecer o acolhimento e a inserção dos estudantes na cultura acadêmica, com a intenção de minimizar dificuldades e de potencializar a aprendizagem dos estudantes tutorados. O segundo consenso diz respeito às contribuições positivas da tutoria para a formação de pesquisadores e docentes do Ensino Superior.

Além da pesquisa bibliográfica realizada, utilizou-se também, para a produção dos dados deste estudo, um questionário contendo três questões abertas, quais sejam: (1) O que você destaca como mais importante no trabalho da tutoria?; (2) Quais contribuições você acha que a tutoria trouxe para você e para seu trabaIho? e (3) O que você sugere para melhorar o processo de tutoria?

Com o objetivo de investigar as contribuições da tutoria para tutores e tutorados do Formep, buscou-se amparo na abordagem qualitativa de pesquisa que, segundo André (2008, p. 47), tem como foco de atenção "o mundo dos sujeitos, os significados que atribuem às suas experiências cotidianas, sua linguagem, suas produções culturais e suas formas de interações sociais".

Os sujeitos da pesquisa são tutores, doutorandos dos programas de pós-graduação em Educação: Psicologia da Educação e em Educação: Currículo, ambos da PUC-SP, e tutorados, alunos matriculados nas três primeiras turmas do Formep, também da PUC-SP.

O grupo de alunos tutorados é constituído por profissionais que, em sua maioria, exercem as funções de gestores de órgãos centrais da Educação, diretores escolares, coordenadores pedagógicos e professores. 
O questionário foi encaminhado, via Google Docs, para 116 alunos, que participaram da tutoria entre os anos de 2013 e 2016, e para 13 tutores. Desse total, 45 alunos e 13 tutores contribuíram com a pesquisa.

No presente trabalho, foi utilizada uma parte dos dados produzidos, em função do recorte adotado na produção deste artigo. Os nomes atribuídos aos participantes são fictícios.

Os dados foram analisados com base no objetivo central do artigo: investigar e discutir as contribuições da tutoria para tutores e tutorados do Formep.

O conteúdo que atendia ao objetivo foi lido diversas vezes. Dele, extraíram-se os tópicos que orientam a organização das seções a seguir: A tutoria na visão dos tutores e A tutoria na visão dos tutorados.

O referencial teórico utilizado fundamentou-se na abordagem sócio-crítica da formação de professores e na psicologia sócio-histórica.

\section{RESULTADOS E DISCUSSÃO}

A investigação realizada com tutores e tutorados revelou que a tutoria se configurou como uma atividade que contribuiu para a aprendizagem de todos os sujeitos envolvidos na pesquisa, e não apenas para os tutorados, o que sugere haver um movimento de dialeticidade na interação pedagógica entre os participantes da tutoria acadêmica do Formep, que não poderia ser negligenciada.

Por uma questão de ordem meramente didática, apresentaremos as considerações feitas pelos tutores, seguida daquelas realizadas pelos alunos tutorados, para então retomar a relação dialógica entre elas.

\section{A tutoria na visão dos tutores}

Um destaque importante feito pelos tutores diz respeito àquilo que puderam aprender no desempenho de sua atividade:

Na tutoria, eu tive oportunidade de compartilhar experiências com profissionaisquetrazem diferentesexperiênciasdaeducaçãobásica, equetêmum objetivo em comum: investigar e ressignificar a própria prática (Tutor João).

Os tutores apontaram, ainda, que a tutoria contribuiu para que vivessem experiências que, embora desafiadoras, colaboraram para a sua própria formação:

Para o tutor é extremamente desafiador participar com o tutorando das definições de seu objeto de investigação, indicar referências $e$ até orientar sobre as fontes de busca de informações (Tutora Sílvia).

Cabe destacar que a afirmação da tutora Sílvia também pode sugerir que a tutoria contribuiu para que os tutores se formassem como potenciais orientadores de trabalhos de pesquisa, futuramente.

Além disso, os momentos de tutoria configuraram-se como espaços de aprendizagem da docência superior para os tutores e constituíram-se lócus de aprendizagem para o desenvolvimento de conhecimentos necessários para a docência no Ensino Superior:

Eu não tinha experiência na docência do ensino superior. Por isso, a tutoria me possibilitou entrar em contato com as dificuldades experimentadas pelos discentes que ingressam na pós-graduação (Tutora Marina). 
Os tutores destacaram, ainda, que o trabalho em grupo com seus pares foi essencial para o enfrentamento dos desafios com que se depararam:

Eu quero destacar o trabalho em grupo com outros colegas. Em muitos momentos, se não fosse isso, eu teria tido muitas dificuldades $e$ não saberia o que fazer ou como agir em alguns casos (Tutora Jane).

A troca de experiência na elaboração das atividades, com os colegas da pós-graduação, e no trabalho com os alunos foi um ponto muito positivo (Tutora Sílvia).

Os depoimentos dão indícios de que houve colaboração entre os tutores. Ao trabalharem juntos, puderam refletir e tomar decisões que lhes permitiram a construção de conhecimentos, o que não aconteceria, se tivessem trabalhado isoladamente.

Além disso, cabe acentuar, mais uma vez, que os tutores também destacaram as aprendizagens construídas com os tutorados, cujas relações foram atravessadas não apenas por conhecimentos de ordem cognitiva, como também envolveram a dimensão afetiva:

Ao longo do tempo, fortalecemos laços de amizade. Um dia, uma aluna participante da tutoria, sabendo do meu objeto de investigação do doutorado, encontrou um texto correlato à minha pesquisa e fez questão de compartilhar comigo. Eu aprendo muito com essa atividade (Tutor João).

Analisaremos, a seguir, algumas contribuições da tutoria para os alunos tutorados do Formep.

\section{A tutoria na visão dos tutorados}

Para os alunos tutorados, a participação na tutoria trouxe importantes contribuições para que conseguissem superar os desafios envolvidos em seu processo de inserção no mestrado e, assim, sobrevivessem na pós-graduação. Para eles, as atividades desenvolvidas com os tutores contribuíram para que definissem seu tema de pesquisa e compreendessem os gêneros textuais comuns na academia. Os depoimentos a seguir ilustram isso:

O que é mais positivo na tutoria, para mim, é o papel dos tutores de atender e orientar os alunos ingressantes nos seus períodos iniciais da pós-graduação (Tutorado Jorge).

Eu quero destacar a devolutiva que meu tutor me deu, a partir da leitura do "Tema e eu". Isso me ajudou muito. Me mostrou que eu tinha muita coisa para melhorar, mas que eu não estava sozinha (Tutorada Catarina).

Outro aspecto que merece destaque diz respeito também à imbricação entre as dimensões afetiva e cognitiva, que permearam o trabalho dos tutores, na visão dos tutorados:

Eu quero destacar: o comprometimento dos tutores conosco; a sinceridade dos tutores em assumir que determinadas dúvidas necessitariam de ser compartilhadas com outras pessoas, pois naquele momento não tínhamos condições de chegarmos a resposta; a parceria demonstrada entre o grupo de tutores e a iniciação ao nosso trabalho de pesquisa (Tutorado Pedro). 
O depoimento acima sugere que as interações com os tutores foram positivas e que, embora houvesse pontos que poderiam melhorar, as considerações positivas foram essenciais para que todos - tutores e tutorados -, pudessem aprender juntos:

Da minha relação com os tutores eu destaco a dialogicidade, a capacidade de lidar com as expectativas e medos de quem ingressa no mestrado. Isso é muito importante (Tutorada Gilda).

Eu acho que merece destaque o grande interesse [dos tutores] em ajudar. Mesmoquenãosoubessemumassuntoemprofundidade, sempresedispõem a pesquisar, a aprofundar. E todos aprendemos juntos (Tutorada Maria).

Ainda que tratem de uma coisa que sabem muito. E olha que eles sabem coisas, eu destaco a consideração em relação ao outro (Tutorada Janaína).

Diante das afirmações dos tutorados e analisando-as em conjunto com as dos tutores, observa-se que há uma relação de transitividade em suas interações, o que nos permite inferir que a tutoria acadêmica do Formep vem se constituindo um espaço de aprendizagem mútua do habitus acadêmico (BORDIEU, 2004), que não envolve apenas o domínio de conhecimentos para obter desempenho satisfatório na pós-graduação, ou de ler e produzir textos com êxito, mas também de compreender e conseguir lidar com os processos de socialização que fazem parte da vida acadêmica. Esse processo, no contexto investigado, parece ter sido facilitado pelo destaque dos afetos positivos que marcaram as interações entre os tutores e tutorados que ofereceram seus depoimentos.

Diante disso, podemos afirmar que o Formep vem se constituindo um espaço de formação colaborativo e crítico.

\section{CONSIDERAÇÕES FINAIS}

As reflexões e as problematizações apresentadas neste artigo apontaram evidências acerca da importância da atividade de tutoria acadêmica realizada no Programa de Mestrado Profissional em Educação: Formação de Formadores (Formep), da PUC-SP. Constatou-se que a atividade tem se constituído um espaço de aprendizagem colaborativa e crítica tanto para tutores quanto para tutorados, pois permite, na relação de interação estabelecida entre eles, um modo peculiar de aprender.

A análise das respostas dos tutores e dos tutorados, fornecidas no questionário, indicou que o processo de aprendizagem colaborativa e crítica vivido na atividade de tutoria foi apropriado pelos participantes como algo afetivo, prazeroso e produtor de avanço acadêmico, o que corrobora nossa proposição da necessidade de investir-se cada vez mais em qualificar a participação de tutores e tutorados na referida atividade.

Quando falamos em qualificar a participação dos envolvidos na atividade de tutoria acadêmica, estamos chamando atenção para aspectos da relação entre tutores e tutorados que são primordiais para promover a aprendizagem e o desenvolvimento de ambos, por exemplo, a presença do par mais experiente. Conforme nos alerta Vigotski, ter esse par presente em uma determinada situação de aprendizagem não garante, por si só, a aprendizagem do outro - no caso, do tutorado -, razão pela qual entendemos que se deve investir na contínua formação dos tutores para o exercício dessa função.

Outro aspecto é que o espaço de participação colaborativa deve elevar como premissa a crítica, entendendo-a como mola propulsora da aprendizagem significativa. Não há como se aprender bem, como 
significar conteúdos, sem passar pelo crivo crítico de si e do outro. É imprescindível ter em mente que a crítica é inerente ao processo de aprendizagem, pois funciona como um sinal de alerta da nossa incompletude humana. Contudo, sabemos o quão é difícil, no cotidiano das relações, ter a crítica como fundamento.

Diante do exposto, e para finalizarmos este artigo, colocamos como proposta para avançar nas reflexões críticas empreendidas por nós um aprofundamento de estudos acerca de aspectos da relação de mediação estabelecida entre tutor e tutorados que evidenciem a presença da crítica e suas possíveis contribuições para o processo de aprendizagem. 


\section{REFERÊNCIAS}

ANDRÉ, M. Estudo de caso em pesquisa e avaliação educacional. 3. ed. Brasília: Liber Livro Editora, 2008.

Professores do PED criam Mestrado Profissional em Educação: Formação de Formadores. Psicologia da Educação, São Paulo, 35, 2o sem. de 2012, p. 215-220. Disponível em: http://pepsic.bvsalud.org/pdf/psie/n35/n35a11.pdf. Acesso em: 01 set. 2016.

. A formação do pesquisador da prática pedagógica. Plurais Revista Multidisciplinar, Salvador, v. 1, n. 1, p. 30-41, jan./abr. 2016. Disponível em: http://www.revistas.uneb.br/index.php/plurais/article/view/2300/1605. Acesso em: 01 set. 2016.

ANDRÉ, M.; PEREIRA, R.; PRÍNCEPE, L. M.; ARANHA, E. M. G. Tutoria acadêmica no mestrado profissional: um aprendizado compartilhado. Revista da FAEEBA - Educação e Contemporaneidade, Salvador, v. 25, n. 47, p. 37-50, set./dez. 2016. Disponível em: https://www.revistas.uneb.br/index.php/faeeba/article/view/3207/2076. Acesso em: 14 out. 2017.

ANDRÉ, M.; PRÍNCEPE, L. O lugar da pesquisa no mestrado profissional em educação. Educar em Revista, Curitiba, $n$. 63, p. 103-117, jan./mar. 2017. Disponível em: http://www.scielo.br/pdf/er/n63/1984-0411-er-63-00103.pdf. Acesso em: 11 out. 2017.

BASTOS, A. V. B.; TOURINHO, E. Z.; YAMAMOTO, O. H.; MENANDRO, P. R. M. Documentos e debates. Réplica 1 - Formar docentes: em que medida a pós-graduação cumpre esta missão? Revista de Administração Contemporânea, Curitiba, v. 15, n. 6, p. 1152-1160, nov./dez. 2011.

BORDIEU, P. Os usos sociais da ciência: por uma sociologia clínica do campo científico. São Paulo: Editora UNESP, 2004.

BRASIL. Lei no 4.024, de 20 de dezembro de 1961. Fixa as Diretrizes e Bases da Educação Nacional. Disponível em: http://www2.camara.leg.br/legin/fed/lei/1960-1969/lei-4024-20-dezembro-1961-353722-publicacaooriginal-1-pl. html. Acesso em: 25 set. 2017.

Conselho Federal de Educação (CFE). Parecer no 977, de 03 de dezembro de 1965. Definição dos cursos de pós-graduação. Disponível em: https://www.capes.gov.br/images/stories/download/legislacao/Parecer_CESU_977_1965. pdf. Acesso em: 08 set. 2016.

. Fundação Coordenação de Aperfeiçoamento de Pessoal de Nível Superior (CAPES). Portaria no 80, de 16 de dezembro de 1998. Dispõe sobre o reconhecimento dos mestrados profissionais e dá outras providências. Disponível em: https://www.capes.gov.br/images/stories/download/avaliacao/avaliacao-n/1892015-Portaria-CAPES-080-1998. pdf. Acesso em: 12 set. 2016.

Portaria Normativa no 7, de 22 de junho de 2009. Dispõe sobre o mestrado profissional no âmbito da Fundação Coordenação de Aperfeiçoamento de Pessoal de Nível Superior - Capes. 2009a. Disponível em: https://www. capes.gov.br/images/stories/download/legislacao/Revogada-Portaria-Normativa-n_7-22-de-junho-2009-Mestrado-Profissional.pdf. Acesso em: 28 set. 2017.

Portaria Normativa no 17, de 28 de dezembro de 2009. Dispõe sobre o mestrado profissional no âmbito da Fundação Coordenação de Aperfeiçoamento de Pessoal de Nível Superior - Capes. 2009b. Disponível em: http://www. capes.gov.br/images/stories/download/legislacao/PortariaNormativa_17MP.pdf. Acesso em: 28 set. 2017.

Ministério da Educação. Portaria no 389, de 23 de março de 2017. Dispõe sobre o mestrado e doutorado profissional no âmbito da pós-graduação stricto sensu. Disponível em: http://www.capes.gov.br/images/stories/download/legislacao/24032017-PORTARIA-No-389-DE-23-DE-MARCO-DE-2017.pdf. Acesso em: 06 out. 2017.

CURY, C. R. J. Quadragésimo ano do parecer CFE no 977/65. Revista Brasileira de Educação, n. 30, p. 7-20, set./dez. 2005. Disponível em: http://www.scielo.br/pdf/rbedu/n30/a02n30.pdf. Acesso em: 28 set. 2017.

CHAIKLIN, S. A zona de desenvolvimento próximo na análise de Vigotski sobre aprendizagem e ensino. Trad. Juliana Campregher Pasqualini. Psicologia da Educação, São Paulo, v. 16, n. 4, p. 659-675, 2011.

DOCUMENTO do Forpred: relatório das condições e perspectivas dos mestrados profissionais na área de educação. 2013. Disponível em: http://www.anped.org.br/sites/default/files/relatorio_comissao_forpred_2013.pdf. Acesso em: 03 out. 2017. 
FRÍAS, J. C. T. El papel de la tutoría en la formación de habitus científicos en estudiantes de doctorado en educación. 2012. Disponível em: http://www.publicaciones.cucsh.udg.mx/pperiod/cgraduados/pdf/2012/el_papel_de_la_tutoria.pdf. Acesso em: 02 jun. 2015.

JIMENEZ-VASQUEZ, M. S. Trayectorias profesionales de egresados del doctorado en Educación de la Universidad Autónoma de Tlaxcala: una nálisis de las funciones, productividad y movilidadenel mercado académico. Perfiles educativos, 2014, v. 36, n. 143, p. 30-48. Disponível em: http://www.scielo.org.mx/scielo.php?script=sci_arttext\&pi$\mathrm{d}=$ S0185-26982014000100003. Acesso em: 02 jun. 2015.

MAGALHÃES, M. C. C. O método para Vygotsky: a zona proximal de desenvolvimento como zona de colaboração e criticidade criativas. In: SCHETTINI, R. H. et al. (Orgs.). Vygotsky: uma revisita no início do século XXI. São Paulo: Andross, 2009. - (Linguagem em movimento), p. 53-78.

PENTEADO, M. E. L. A dimensão subjetiva da docência: significações de professores e gestores sobre "ser professor", produzidas em um processo de pesquisa e formação. 2017. 227f. Tese. (Doutorado em Educação: Psicologia da Educação) - Pontifícia Universidade Católica de São Paulo, São Paulo, 2017.

PRESTES, Z. R. Quando não é quase a mesma coisa: traduções de Lev Semionovitch Vigotski no Brasil. 2010. 295f. Tese (Doutorado em Educação) - Universidade de Brasília - UnB, Brasília, 2010.

PUC-SP. Reitoria. Regulamento do Programa de Estudos Pós-Graduados em Educação: Formação de Formadores, da Faculdade de Educação da PUC-SP. 2015. Disponível em: http://www.pucsp.br/sites/default/files/download/posgraduacao/programas/educacaoformacaoformadores/deliberacao_do_consun_no_16-2015.pdf_novo_0.pdf. Acesso em: 02 out. 2017.

REIS, A. T.; SIGALLA, L. A. A.; PENTEADO, M. E. L. Sobre as origens do Mestrado Profissional em Educação: Formação de Formadores (FORMEP), da PUC-SP - tecendo memórias... In: Educere. XII Congresso Nacional de Educação. 2015, Curitiba/PR. Anais... p. 7058-7071. Disponível em: http://educere.bruc.com.br/arquivo/pdf2015/17497_9133.pdf. Acesso em: 31 ago. 2016.

RENDÓN GIRALDO, N. E. Proceso de autoevaluación de posgrado: proceso de autoevaluación de posgrado - aplicación de una metodología. Revista Interamericana de Bibliotecología, 2008, v. 31, n. 1, p. 135-160.

SIGALLA, L. A. A. Tutoria acadêmica entre pares na pós-graduação stricto sensu: contribuições desse espaço coletivo-colaborativo de trabalho e formação. A experiência do Formep, na PUC-SP. 2018. 251f. Tese. (Doutorado em Educação: Psicologia da Educação) - Pontifícia Universidade Católica de São Paulo, São Paulo, 2018.

TORRES, E. O.; SANCHEZ, M. L. A. M. El proceso de enseñanza-aprendizaje para adultos en la educación posgraduada. 2008. Disponível em: www.rieoei.org/deloslectores/1934Ortiz.pdf. Acesso em: 12 ago. 2018.

VALDÉS-CUERVO, A. A.; SÁNCHEZ-ESCOBEDO, P. A.; YÁÑEZ-QUIJADA, A. I. Perfiles de estudiantes mexicanos com aptitudes intelectuales sobresalientes. Acta Colombiana de Psicología, 2013. Disponível em: http://www.redalyc.org/ articulo.oa?id=79829185003. Acesso em: 02 jun. 2015.

VIGOTSKI, L. S. Obras escogidas III: problemas del desarrollo de la psique. Visor Distribuciones: Madrid, 1995.

Vigotski: Manuscrito de 1929. Educação \& Sociedade, Campinas, v. 21, n. 7, p. 21-44, jul. 2000.

Teoria e método em psicologia. São Paulo: Martins Fontes, 2004.

Obras escogidas IV: psicología infantil. 2. ed. Madri: Visor, 2006.

A formação social da mente: o desenvolvimento dos processos psicológicos superiores. 7. ed. São Paulo: Martins Fontes, 2007.

A construção do pensamento e da linguagem. 2. ed. São Paulo: Editora WMF Martins Fontes, 2009.

Quarta aula: a questão do meio na pedologia. Psicologia USP, São Paulo, 21(4), p. 681-701, 2010. 